\title{
Comitês de governança de tecnologia da informação na administração pública federal brasileira: fatores críticos de sucesso
}

\author{
Marcelo Silva Cunha \\ Universidade Católica de Brasilia (UCB)
}

João Souza Neto

Universidade Católica de Brasília (UCB)

Nos últimos anos, na esfera pública federal brasileira, os órgãos de controle externo e interno vêm enfatizando e estimulando a adoção de estruturas de governança de tecnologia da informação (GTI) junto a toda administração pública federal (APF). O presente trabalho identificou, avaliou (com a participação de especialistas em GTI na APF), e classificou os fatores críticos de sucesso (FCS) para a atuação dos comitês de GTI da APF em dois níveis: estratégico e diretivo. Partiu-se de uma lista universal com quarenta FCS, extraída da literatura especializada, e promoveu-se a avaliação desses por meio do método Delphi. No decorrer das rodadas Delphi, novos FCS foram incluídos pelos especialistas na lista original. Ao final da pesquisa, obteve-se uma lista ordenada por importância relativa de dez FCS para os comitês estratégicos de GTI na APF e doze FCS para os comitês diretivos de GTI na APF.

Palavras-chave: administração pública, governança de TI, governança corporativa, tecnologia da informação

Artigo recebido em janeiro de 2014. Versão final em julho de 2014. 
Comité de gobernanza de tecnología de la información en la administración pública federal brasileña: factores críticos de êxito

En los últimos años, la esfera pública federal brasileña, los órganos de control interno y externo han hecho hincapié y fomentado la adopción de marcos de gobernanza de TI (GTI) a lo largo de toda la administración pública federal (APF). Este trabajo ha identificado, evaluado (con la participación de expertos en el GTI APF), y clasificado los factores críticos de éxito (CSF) para el trabajo de los Comités GTI APF en dos niveles estratégico y directivos. A partir de una lista universal de cuarenta FCS, extraída de la literatura, se promovió la evaluación de estos a través del método Delphi. Durante las rondas Delphi, nuevos FCS fueron incluidos por los expertos en la lista original. Al final del estudio, se obtuvo una lista ordenada por importancia relativa de diez FCS para los Comités Estratégicos GTI y doce en la APF FCS para los Comités Directivos GTI en la lista de APF.

Palabras clave: administración pública, gobernanza de tecnologia de la información, gobernanza corporativa, tecnologías digitales de la información

\section{IT Governance Committees in the Brazilian public sector: the critical success factors}

In recent years, in the Brazilian Public sector, the Internal and External Control Agencies have been stressing and encouraging the adoption of IT governance frameworks (ITG) along the entire Federal Public Administration (FPA). This paper has identified, assessed (with the participation of experts in IT Governance in the Brazilian Public Sector), and classified the Critical Success Factors (CSF) for the work of the ITG Committees on two levels: strategic and directive. Starting from a universal list of forty CSF extracted from the specialized literature, an assessment of these was conducted using the Delphi Method. During the Delphi rounds, new FCS were included by experts in the original list. At the end of the study, a list in order of relative importance of ten CFS for ITG Strategic Committees and twelve CFS for ITG Directive Committees was obtained.

Keywords: public administration, IT governance, corporate governance, information technology 


\section{Introdução}

Hoje, as organizações dependem sobremaneira da efetividade das suas áreas de tecnologia da informação (TI) e, algumas, até mesmo para sua sobrevivência. No entanto, apesar de seu avanço e maturidade, essas tecnologias inseridas nos contextos organizacionais são percebidas como onerosas e dissociadas das missões, objetivos estratégicos e metas organizacionais. Não se percebe um claro retorno de valor da TI.

Contrapondo tudo isso, a governança de tecnologia da informação (GTI) está relacionada ao uso racional e efetivo de TI para sustentar e garantir o cumprimento dos interesses estratégicos das organizações e, nesse sentido, se apresenta como prática capaz de mitigar esse aparente desgoverno.

Estudo do Instituto de Governança da Tecnologia da Informação - ITGI (2004, p.6) revelou que mais de $80 \%$ dos CIOs (Chief Information Officer - Diretor de TI) reconhecem a necessidade de uma GTI melhor, a fim de endereçar adequadamente a estratégia da organização.

Pesquisa de Weill e Ross (2004, p.3) confirmou a importância da GTI, mostrando que empresas com GTI considerada superior têm um ganho $20 \%$ superior àquelas com governança insuficiente, diante de objetivos estratégicos similares.

No Brasil, Walton Alencar Rodrigues, Ministro-Presidente do Tribunal de Contas da União durante o biênio 2007-2008, por sua vez afirmou (BrASIL, 2008b, p.5):

Um dos grandes desafios da Administração Pública Federal na atualidade é a elevação do seu grau de governança. O Tribunal de Contas da União, como órgão de controle externo, tem um papel de destaque no aperfeiçoamento dessa área. Nesse contexto, a governança de tecnologia da informação (TI) é essencial para que se atinja esse objetivo. A TI é o verdadeiro motor das organizações modernas, podendo tanto impulsioná-las muito adiante como emperrar o seu progresso.

Tem-se, portanto, que a necessidade e a oportunidade da GTI é ponto bem aceito, no que diz respeito à APF. Mas como abordá-la de forma pragmática e efetiva? Luftman (2003, p.164) pontua que o estabelecimento de comitês diretivos de TI é considerado como "boa prática" de mecanismos de GTI para a tomada de decisões relacionadas aos investimentos e uso de TI na organização. Caporarello (2008, p.41) considera esses comitês diretivos de TI como a estrutura-chave do sistema de GTI e que, dessa maneira, esses comitês espelham o papel estratégico da TI na organização.

Nos últimos anos, a literatura acadêmica destaca, entre os diversos mecanismos de GTI, aqueles baseados em grupos colegiados de profissionais: comitês de GTI 
(Huang, Zmud e Price, 2010; Nfuka e Rusu, 2010; Prasad, Heales e Green, 2009; Ali e Green, 2005; Gupta e Raghunathan, 1989; Nolan e Mcfarlan, 2005; Doughty, 2002; Karimi et al., 2000), sendo esse o objeto deste estudo.

É importante salientar que existe uma grande profusão de nomes para esses comitês e os mais comumente encontrados são comitê estratégico (Strategic), comitê diretivo (Steering), comitê de supervisão (Oversight). Doravante se fará genericamente referência a esse mecanismo como comitê de GTI (CGTI).

No âmbito da APF, a utilização desses comitês de GTI é corroborada tanto pelo Tribunal de Contas da União (TCU) quanto pela Secretaria de Logística e Tecnologia da Informação (SLTI) do Ministério do Planejamento, Orçamento e Gestão (MPOG) que, em suas deliberações e normativos, exaram a necessidade imperativa da constituição, implantação e o pleno funcionamento desses comitês de GTI.

Assim, numa época em que a TI tornou-se fator indispensável para habilitar os governos a oferecerem serviços melhores aos seus cidadãos, de forma mais ética, transparente, eficiente e sustentável, sob um prisma econômico, ambiental e social, tem-se que a GTI desponta como uma capacidade crítica para o setor público e suas lideranças, em busca de criar e entregar mais valor para os seus cidadãos por meio do uso efetivo da TI.

\section{Revisão da Literatura}

Foi realizada pesquisa bibliográfica utilizando a base de artigos científicos da Coordenação de Aperfeiçoamento de Pessoal de Nível Superior (Capes) ${ }^{1}$. Nessas bases científicas, foram realizadas buscas, sem a definição de horizonte histórico, nas seguintes áreas de conhecimento: Multidisciplinares, Ciências Sociais Aplicadas e Engenharias. Colheram-se ao todo resultados de buscas em 20 (vinte) bases.

Outros valiosos recursos, como as bases de teses e dissertações de universidades no Brasil (PUC-Rio, UCB, UFF, UFRGS, UFRJ, UFSC, UnB e USP) e no Exterior (África do Sul: Nelson Mandela Metropolitan University e University of Pretoria; Austrália: Macquarie University e Queensland University of Technology; Portugal: Universidade do Minho e Universidade Técnica de Lisboa) também foram utilizados.

Nesta pesquisa não foram identificados na literatura trabalhos que estudem, por meio de métodos qualitativos e/ou quantitativos, a atuação desses comitês na APF brasileira.

${ }^{1}$ A base de artigos mencionada está disponível em www.periodicos.capes.gov.br 


\section{Contextualização do Problema}

O Tribunal de Contas da União (TCU), nos últimos cinco anos, com base nos orçamentos anuais cada vez maiores (decorrentes do uso intensivo e maciço de TI), na complexidade do tema e na ocorrência frequente de irregularidades e denúncias, passou a debruçar-se sistematicamente sobre o emprego e as contratações de tecnologia da informação e comunicações (TIC) realizadas pelos órgãos públicos da APF.

Como parte desse trabalho sistemático, e diante das diretrizes traçadas pelo Acórdão no 1.603/2008 - TCU-Plenário (BRASIL, 2008a, p. 49), realizou-se no ano de 2012 o Levantamento de Auditoria da TC no 007.887/2012-4, cujo objeto de fiscalização é a GTI na APF (BRASIL, 2012). Esse levantamento se deu num universo de 350 órgãos jurisdicionados ao TCU, com um total de 286 que responderam a ambos os levantamentos: o de 2010 e o de 2012. Esses órgãos foram submetidos a um questionário off-line com 36 questões, subdivididas em 494 itens, contemplando as oito dimensões do GesPública (BRASIL, 2005): liderança, estratégias e planos, cidadãos, sociedade, informações e conhecimento, pessoas, processos e resultados. 0 GesPública é o Programa Nacional de Gestão Pública e Desburocratização e foi criado com a finalidade de contribuir para a melhoria da qualidade dos serviços públicos prestados aos cidadãos e para o aumento da competitividade do País.

A Figura 1 apresenta a comparação dos resultados obtidos em 2010 e 2012 relativos à estrutura de governança de TI dos órgãos.

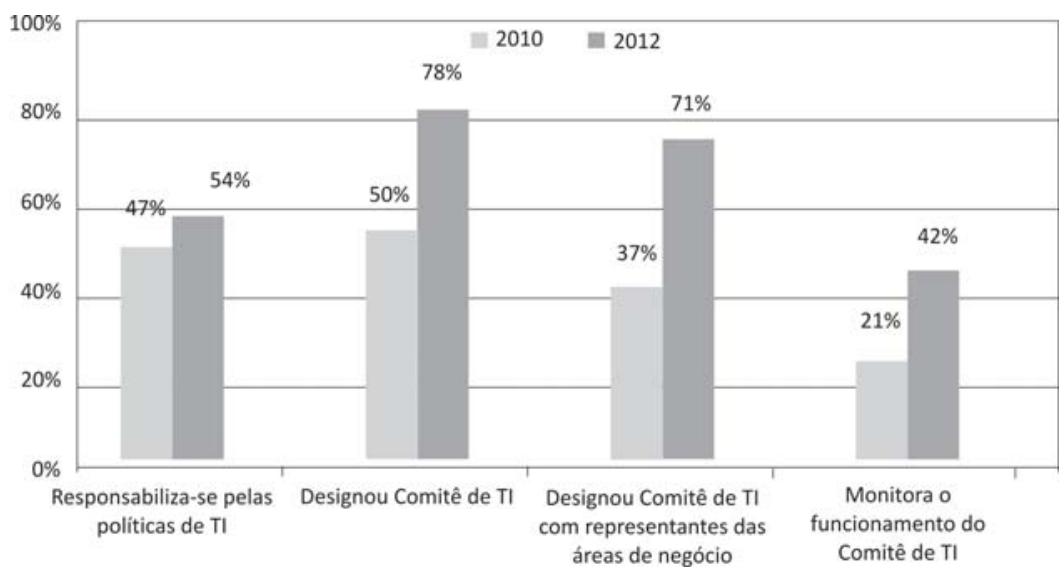

Fonte: TCU (BRASIL, 2012, p. 5).

Figura 1: Gráfico comparativo dos resultados obtidos em 2010 e 2012 relativos à estrutura de governança de TI dos órgãos. 
Conforme se pode constatar, houve evolução no índice em relação ao levantamento anterior, haja vista que, em 2012, 78\% dos participantes declararam ter designado um comitê de TI, contra 50\% em 2010. Contudo, conclui o TCU, ainda é preocupante, em face dos riscos decorrentes da inexistência desse tipo de comitê, que $22 \%$ dos avaliados ainda não o tenham estabelecido. Além disso, entre os que estabeleceram o comitê, $71 \%$ designaram representantes da área de negócio, o que representa evolução em relação a 2010, que indicava apenas $37 \%$. Por outro lado, apenas $42 \%$ monitora o funcionamento do comitê, situação que indica melhora em relação ao levantamento anterior (21\%), mas pouco significativa, haja vista que $58 \%$ das instituições ainda não acompanham e avaliam as atividades dos comitês (BRASIL, 2012, p. 5).

\section{Formulação da Questão de Pesquisa}

Haja vista a falta de efetividade percebida dos comitês de GTI dos órgãos da APF brasileira, cabe então a seguinte questão de pesquisa: como os órgãos da APF brasileira podem melhorar a atuação de seus comitês de GTI?

\section{Objetivo Geral}

É objetivo geral da presente pesquisa: identificar os fatores críticos de sucesso (FCS) que possibilitem melhorias na atuação dos comitês de GTI na APF brasileira e avaliá-los junto a especialistas em GTI.

\section{Governança corporativa de tecnologia da informação}

Van Grembergen e De Haes (2009, p.3) definem e posicionam a governança de tecnologia da informação (GTI) em uma organização qualquer, seja ela do setor privado ou público. Segundo estes autores:

a Governança Corporativa de Tecnologia da Informação (GCTI) é parte integrante da Governança Corporativa (GC) e endereça a definição e implementação, na organização, de processos, estruturas e mecanismos relacionais que habilitam tanto o pessoal de negócio quanto o pessoal de $\mathrm{Tl}$ a executarem suas responsabilidades em suportar o alinhamento estratégico e a criação de valor de negócio a partir dos investimentos habilitadores da TI. (VAN GREMBERGEN; De HAEs, 2009, p.3) (siglas e grifos nossos)

A ISO, em 2008, também trilhou esse caminho com a publicação do padrão mundial ISO/IEC 38.500:2008 (Corporate Governance of Information Technology) que, em seus seis princípios, estabelece os papéis e responsabilidades tanto da 
área de $\mathrm{TI}$, como da área de negócio. Em 2009, inspirada pela ISO, a Associação Brasileira de Normas Técnicas (ABNT) publicou o padrão brasileiro: ABNT NBR ISO/IEC 38.500:2009 (Governança Corporativa da Tecnologia da Informação).

De Haes e Van Grembergen (2009, p.21) alertam que “essa súbita e revolucionária mudança de foco e nomenclatura implica numa verdadeira quebra de paradigma na mente das pessoas do negócio".

Isso marca uma transição e enfatiza o posicionamento adequado da GTI como sendo parte integrante e indissociável da governança corporativa (GC). Trata-se, portanto, de tema relacionado ao negócio da organização. Utilizou-se o termo "transição" para expressar a mudança do conceito, a quebra de paradigma referida pelos autores. Utilizou-se também a expressão "enfatiza o posicionamento" no sentido de corrigir interpretações. Historicamente, em função de o nome conter a expressão "tecnologia da informação", interpretava-se que a GTI era essencialmente tarefa da TI. Isso se constitui num equívoco, pois a GTI não é tarefa apenas da TI, ao contrário, é tarefa do negócio, da alta administração da organização, da GC.

Portanto, nesta pesquisa, ao se mencionar a GTI, se está fazendo referência a uma parte, ou um subconjunto, da GC. Em verdade, se está falando da Governança Corporativa de Tecnologia da Informação (GCTI), que busca alinhar o planejamento e as decisões da área de TI às estratégias de GC e às demandas dos clientes corporativos.

\section{Conceituações de Comitês de Governança de Tecnologia da Informação}

Para os comitês de governança de tecnologia da informação, existe uma grande proliferação de nomenclaturas (estratégico - strategic, diretivo - steering, de supervisão - oversight, de auditoria - audit etc.), papéis, funções, composições, níveis hierárquicos, temporalidade, além de outras peculiaridades. Outra característica que se depreende é que essas nomenclaturas não estão necessariamente associadas ao nível hierárquico do comitê. Por exemplo, para Luftman (2003, p. 171) o comitê diretivo (steering commitee) pode ter níveis estratégico, tático e operacional. Já para Van Grembergen, De Haes e Guldentops (2004, p.22) o comitê diretivo (steering commitee) é de nível tático e o comitê estratégico (strategic commitee) é de nível estratégico.

Portanto, na literatura ainda não existe consenso sobre a nomenclatura apropriada, sua relação com o nível hierárquico em que o comitê se insere e suas atribuições, composição e alçada decisória. Mas então o que esses comitês têm em comum?

i. Todos estão diretamente ou indiretamente ligados à boa governança de $\mathrm{TI}$, à luz das necessidades do negócio, buscando entregar resultados, direcionando a organização e endereçando consistentemente os domínios da GTI: alinhamento 
estratégico, entrega de valor, gestão de recursos, gestão de riscos e monitoração de desempenho.

ii. São organismos colegiados formalizados e compostos pelas principais lideranças formais e informais da organização, em especial pela alta administração, pela diretoria executiva (CXO), pela área de $\mathrm{TI}$ e pelos principais demandantes do negócio.

iii. Assessoram a alta administração ou board, bem como outros setores e colegiados da organização, em sua responsabilidade de governar, além de supervisionar a TI e a corporação, como um todo.

iv. Agem como um veículo de integração de toda a organização.

v. Podem atuar primordialmente em um dos três níveis hierárquicos dentro da estrutura da organização, i.e., nível estratégico, nível tático ou executivo e nível operacional. Eventualmente, dependendo de suas atribuições, podem realizar funções de outros níveis.

vi. Alguns são permanentes e outros são temporários, essencialmente ligados a projetos de grande envergadura.

\section{Alçada de decisão e composição dos Comitês de Governança de Tecnologia da Informação}

Segundo Bowen (2007, p.196), a essência da GTI reside em prover alinhamento entre o negócio e a TI. Dessa forma, o efetivo intercâmbio de ideias e visão compartilhada dos objetivos de negócio e da TI permite que estratégias organizacionais sejam harmoniosamente trabalhadas e adaptadas. Os comitês de GTI apresentam-se, então, como fórum privilegiado, em função da sua natureza constitutiva e da sua representatividade "transorganizacional", para que essas ações ocorram.

A alçada de decisão de um comitê depende, sobretudo, da organização e do que se espera do comitê, i.e., do modus operandi da organização e do seu board e das atribuições do colegiado propriamente ditas. Assim, o comitê poderá ter caráter decisório com relação a todas ou algumas de suas atribuições, ou assistir e/ou assessorar as lideranças formais da organização, em especial o board, que de fato são aqueles que decidem. A implementação é feita, portanto, caso a caso.

O "Guia para Criação e Funcionamento do Comitê de TI" (BRASIL, 2011, p.14), por exemplo, recomenda que os comitês tenham caráter deliberativo, a saber: "se o Comitê for apenas consultivo, resultará apenas em conselhos e pareceres de determinados assuntos, o que poderá descaracterizar a funcionalidade do Comitê de TI na tomada de decisão". Naturalmente essa é uma visão da SLTI/MPOG, mas, de certa forma, expressa uma motivação para que o comitê tenha caráter decisório. 
Van Grembergen, De Haes e Guldentops (2004, p.23), por sua vez, defendem que a alçada de decisão para ambos os comitês seja essencialmente consultiva e de supervisão. Dessa forma, esses comitês atuam, de fato, como uma extensão do board, ou da alta administração. Afinal, esse último é de direito, de acordo com alguns autores, o organismo responsável por governar a TI na organização e, no caso, devidamente assessorado pela estrutura colegiada de comitê de GTI.

Com relação a sua composição, além da alta administração, gestão estratégica e de $\mathrm{TI}$, é fundamental que os principais setores demandantes de tecnologia e do negócio estejam representados.

\section{Funcionalidade dos Comitês de Governança de Tecnologia da Informação}

Luftman (2003, p. 171) reconhece três níveis ou tipos de comitês diretivos:

i) Estratégico: com executivos seniores traçando a direção de longo prazo; ii) Tático: planejamento e gestão de médio prazo; e iii) Operacional: decisões do dia a dia. Ainda para esse autor, o papel de um comitê de GTI deve incluir (LUFTMAN, 2003, p. 172):

- Estabelecer claramente o papel da TI no negócio da organização;

- Identificar as conexões (alinhamento) entre as visões estratégicas da organização e da TI;

- Estabelecer os princípios para investimento em TI e definição das metodologias e processos através dos quais os investimentos em TI possam ser realizados, p.ex., apresentação prévia das propostas de investimento ao comitê diretivo, demonstrando que os benefícios de um investimento em $\mathrm{Tl}$ podem indubitavelmente ultrapassar as taxas de retorno da organização;

- Estabelecer guias gerais e políticas de ética que orientem a seleção de alternativas e investimentos em TI;

- Estabelecer princípios arquiteturais e padrões que irão orientar a seleção e entrega de tecnologias específicas;

- Estabelecer metas e métricas para a avaliação do impacto das decisões de investimento em $\mathrm{Tl}$; e

- Prover efetiva comunicação entre os diferentes comitês diretivos, o que é importante para assegurar a sinergia por toda a organização.

\section{Fatores críticos de sucesso}

Trabalhos na área de gestão organizacional e sistemas de informação reconhecem que certos aspectos de uma organização são cruciais para o seu 
sucesso. Esses aspectos, que podem variar, são categorizados sob o termo genérico de fatores críticos de sucesso (FCS), do inglês Critical Success Factors (CSF).

Dada sua importância, os FCS são largamente pesquisados e aplicados em muitas organizações sob diferentes perspectivas, desde um simples projeto, até o direcionamento estratégico de toda a organização (TAN et al., 2007 apud NFUKA, 2010, p. 3).

Guldentops (2004, p. 1), em trabalho a respeito do êxito na implementação de GTI, define e analisa a formação de comitês estratégicos e diretivos de TI como um dos cinco fatores-chave de sucesso para o controle e governança da $\mathrm{TI}$, fato esse que está alinhado com os objetivos dessa pesquisa.

Vezzoni et al. (2011, p. 4) destaca o caráter dinâmico e a falta de consenso na literatura sobre o melhor conjunto de definições para FCS. Admite, entretanto, que existe concordância quanto à essência do conceito: focar em algumas poucas características críticas que realmente tenham condições de interferir em prol da busca de êxito.

Fishman (1998, p. 10 apud JoNker, 2004, p. 58) preconiza que metas bem definidas são críticas para o sucesso de qualquer organização, mas que tão importante quanto defini-las bem é identificar os FCS necessários para o alcance dessas metas.

Abstraindo-se de definições e corroborando com as observações de Vezzoni et al. (2011, p. 4), os FCS:

- são áreas, aspectos ou acontecimentos limitados de êxito ou sucesso que asseguram em boa medida um rendimento competitivo;

- estão diretamente relacionados e em concordância com a visão, a missão e os objetivos da organização a longo prazo;

- podem ser fatores internos (como recursos, habilidades, competências, atributos, condições), ou fatores relacionados com o mercado e o entorno (externos); e

- são áreas de resultados nas quais o rendimento pode ser medido e avaliado.

Bullen (1995, p. 13), em última análise, destaca que o grande valor que o método dos FCS aporta é a habilidade de focalizar a atenção na direção daquilo que se necessita fazer bem para a obtenção de êxito.

Usar-se-á nesta pesquisa a seguinte definição de FCS, fruto da adaptação e fusão das definições de Ferguson e Dickinson (1982, p. 14) e Vieira (2005, p. 47): fatores críticos de sucesso são fatores internos ou externos à organização, que devem ser identificados e reconhecidos, pois dão suporte ou ameaçam o alcance dos seus objetivos ou até mesmo a sua existência. São eventos ou circunstâncias que requerem atenção especial em função da sua importância para a corporação. 
Definem os desafios mais importantes ou ações de governança que devem ser adotadas para colocar sob monitoração e controle a gestão de TI. Determinam as ações mais importantes do ponto de vista do que fazer em nível estratégico, técnico, operacional e processual.

Também é importante salientar aqui a diferença entre fator de sucesso e fator crítico de sucesso. Um fator de sucesso é algo que pode ocorrer (ou não) para se conseguir um objetivo. Considera-se que um fator de sucesso é crítico quando o seu cumprimento é necessário para alcançar os objetivos.

Furlan (1997 apud Roldan, 2007, p. 3) informa que, no Brasil, o termo Critical Succes Factors foi traduzido como fatores críticos de sucesso ou fatores-chave de sucesso. Entretanto, na literatura é possível encontrar alguns autores que diferenciam esses dois termos. Nesta pesquisa, utiliza-se o termo fatores críticos de sucesso com o mesmo significado de fatores-chave de sucesso, sem prejuízo.

\section{Técnicas de identificação de fatores críticos de sucesso}

Não foram encontrados, na literatura, processos únicos e gerais definidos para auxiliar na identificação de FCS. O método proposto por Rockart $(1979$, p. 84) é empírico e baseia-se em entrevistas, provendo técnicas estruturadas que podem ser usadas por entrevistadores na identificação dos FCS e na determinação das informações necessárias aos gestores. Basicamente, os passos do método geral dos FCS são os seguintes:

i. análise do ramo de atuação da organização ou da natureza de atuação da área;

ii. identificação dos FCS;

iii. definição de medidas (quantitativas ou qualitativas) dos FCS; e

iv. definição de sistemas de informação para controle dessas medidas.

Os aspectos mais críticos para a identificação de FCS, segundo Ghemawat (1991, p. 7 apud JONKER, 2004, p. 70), são:

i. a própria identificação: é difícil selecionar os fatores realmente importantes;

ii. causalidade de relações: mesmo quando se identificam as relações, nem sempre está claro o modo como operam ou interagem;

iii. o risco de generalização: por definição, a vantagem competitiva de uma organização, em particular, não pode ser alcançada com a mera adoção daquilo que é reconhecido como fator crítico de sucesso de uma indústria;

iv. inobservância das perspectivas emergentes: nas indústrias, o êxito advém mais frequentemente de mudanças do que da identificação dos FCS atuais. 


\section{Fatores críticos de sucesso para os CGTI}

Nolan (1982, p. 78) realizou uma das primeiras referências ao tema, com base em informações de um survey por ele conduzido. Sua motivação advinha principalmente da crescente descentralização da função "processamento de dados" e da seleção estratégica de sua aplicação nos negócios. Como consequência, grandes processos de mudança ocorreram dentro das organizações que demandavam sólidos estudos em busca da efetividade. Os comitês diretivos, como instrumento de mitigação dos efeitos dessas mudanças, foram a grande aposta da época. Nolan não utilizou o termo "fatores críticos de sucesso", utilizou "diretrizes empíricas", mas de acordo com o conceito de FCS, exposto anteriormente; esses termos, de fato, são equivalentes.

Reck e Reck (1989, p. 90) estabeleceram que o sucesso dos comitês diretivos de sistemas de informação (SI) depende de inúmeros fatores, dos quais eles destacam os mais críticos, que são apresentados no Quadro 1.

Quadro 1: Fatores críticos de sucesso para comitês diretivos de sistemas de informação, segundo Robert e Virginia Reck

\section{Fatores Críticos de Sucesso}

1. Manter um enfoque de negócio.

2. Enfatizar o crescimento pessoal dos membros do comitê.

3. Estabelecer altos níveis de energia e ritmo rápido, objetivo e pragmático nos encontros do comitê.

4. Assegurar que os membros do comitê estejam alinhados com os objetivos do negócio.

5. Manter uma orientação no sentido da ação.

Fonte: RECK e RECK (1989, p. 90).

Drury (1984, p. 257), por sua vez, estabeleceu que "a performance estratégica de um grupo é dependente da maneira como esse é composto e por meio de quais procedimentos, regras, e normas ele opera". Identificou também a necessidade de importar conceitos da literatura de comportamento organizacional para a análise que promoveu. Ponderou ainda que a efetividade desses comitês colegiados depende de fatores como:

i. tamanho;

ii. diferenciação hierárquica;

iii. mudanças na composição; 
iv. estilo de liderança;

v. estruturação dos encontros; e

vi. divisão de tarefas.

\section{Lista Universal de Fatores Críticos de Sucesso para os Comitês de Governança de Tecnologia da Informação}

Extraiu-se da literatura uma lista inicial de FCS. Esses são FCS universais associados a diversas indústrias e diversos contextos. A lista a seguir apresenta 40 afirmações, sob investigação, sobre FCS para a APF brasileira. Originalmente essa lista era composta de 35 FCS que, após o teste-piloto do instrumento de pesquisa, transformaram-se em:

1. A manutenção de um enfoque de negócio.

2. A busca de alinhamento estratégico entre o negócio e a TI.

3. A busca, diante da constante e rápida evolução/mudança tecnológica, pela redução/eliminação de barreiras burocráticas excessivas na organização, com a finalidade de agilizar a entrega de valor pela TI.

4. O estímulo de altos níveis de motivação, rito objetivo e pragmático nos encontros desse colegiado.

5. A manutenção de orientação no sentido de uma atuação proativa.

6. A promoção de mudanças intermediárias de pequeno porte e execução rápida, realizadas de forma pontual e tempestiva.

7. A promoção regular de revisões e avaliações formais a respeito das contribuições da TI para o negócio, assim como a sua divulgação.

8. A promoção regular de rigorosa vigilância, monitoração de deficiências e controle de riscos.

9. O estabelecimento desse colegiado como principal fórum para a priorização de projetos por meio da seleção do que deve ser feito, quando deve ser feito e quanto, em termos de recursos, deve ser alocado.

10. O estabelecimento deste colegiado como principal fórum para a priorização de investimentos através da seleção do que deve ser feito, quando deve ser feito e quanto, em termos orçamentários e financeiros, deve ser investido.

11. O estabelecimento desse colegiado como principal fórum para as discussões entre o negócio e a TI na organização.

12. A divulgação e o compartilhamento do conhecimento gerado nesse colegiado através de toda a organização. 
13. A atuação desse colegiado como veículo para a divulgação e "venda" do valor da TI para o negócio.

14. A atuação desse colegiado na sensibilização e conscientização de todos os níveis da organização sobre a importância da governança de tecnologia da informação.

15. O estímulo à construção de relacionamentos entre o negócio e a TI para o alcance de pleno entendimento mútuo e de senso de parceria.

16. A agilidade no processo de tomada de decisões, de forma que a minuciosa e demorada análise associada ao processo decisório seja realizada previamente às reuniões desse colegiado.

17. O exercício pleno de autoridade e influência desse colegiado no processo de tomada de decisões organizacionais.

18. A atuação desse colegiado no direcionamento e estabelecimento de diretrizes organizacionais.

19. A atuação desse colegiado em caráter consultivo para a alta administração e outros comitês.

20. A liderança formal desse colegiado a cargo da área de negócio (fora da $\mathrm{TI}$ ).

21. A frequência regular de encontros desse colegiado.

22. A duração controlada dos encontros desse colegiado.

23. O número limitado e gerenciável de membros, compatível com o porte da organização.

24. A existência de uma equipe de suporte administrativo (back office) para realização das atividades e tarefas.

25. A existência de uma equipe de suporte técnico (back office) para realização das atividades e tarefas.

26. A divisão e balanceamento das atividades e tarefas, evitando-se a sobrecarga de membros do colegiado em particular.

27. O alinhamento de seus membros com os objetivos estratégicos do negócio.

28. A promoção do crescimento pessoal/profissional de seus membros.

29. A capacitação de seus membros em competências conversacionais (comunicação efetiva - escutar, expor e indagar produtivos - e gestão de compromissos).

30. O fomento entre os membros desse colegiado de aprendizagem compartilhada, respeito mútuo e confiança.

31. A seleção e manutenção de membros com largo conhecimento do negócio, da TI e suas necessidades, bem como das oportunidades de aplicação de TI no negócio. 
32. A seleção e manutenção de membros cooperativos, compromissados e respeitados.

33. A ampla representatividade dos membros desse colegiado com assentos para a alta administração, negócio e TI.

34. A participação nesse colegiado de membros formadores de opinião na organização.

35. A participação nesse colegiado dos principais demandantes do negócio (stakeholders).

36. A participação nesse colegiado de membros da alta administração (board).

37. A participação nesse colegiado de membros da gestão de TI.

38. A responsabilização e imputação de seus membros pelas decisões tomadas.

39. A busca pela equidade entre os membros desse colegiado, na prestação de contas, reconhecimento, responsabilidades, recompensas e incertezas, reforçando um forte espírito de equipe.

40. A manutenção de membro(s) que exerçam o papel de facilitador(es), com a finalidade de prover foco e auxiliar a equipe a se adaptar a processos que busquem alcançar as metas e objetivos traçados.

\section{Metodologia de pesquisa}

A presente pesquisa buscou identificar, ratificar e/ou retificar, além de classificar os fatores críticos de sucesso (FCS) para o efetivo funcionamento dos comitês de governança de tecnologia da informação (CGTI) na administração pública federal (APF) brasileira.

Partindo-se de uma lista inicial de fatores críticos de sucesso universais, extraída da literatura consultada, promoveu-se o processo de ratificação e/ou retificação da mesma com especialistas em governança de tecnologia da informação (GTI) aplicada à APF, utilizando-se para tal o método Delphi.

\section{Método Delphi}

Nesta pesquisa empregou-se o método Delphi que, genericamente, pode ser definido como um método para estruturar um processo de comunicação grupal, de maneira que o processo é efetivo em permitir a um grupo de indivíduos, como um todo, lidar com um problema complexo (Turoff, 1975, p. 3 apud Giovinazzo, 2001, p. 1).

O método Delphi é um processo interativo que coleta e refina julgamentos anônimos de reconhecidos especialistas, usando uma série de questionários e técnicas de análise interligados com feedback (SкuLmoskı et al., 2007). Esse método 
se aplica como instrumento de pesquisa quando não existe completo conhecimento sobre um problema ou fenômeno. É esse o nosso caso, uma vez que não dispomos de conhecimentos específicos sobre os FCS, no caso da "indústria" e administração pública federal (APF) brasileira. O método Delphi funciona especialmente bem, quando o objetivo é melhorar o entendimento de problemas, oportunidades, soluções, ou para desenvolver previsões.

O método estabelece quatro regras básicas: i) o anonimato dos participantes; ii) a representação estatística da distribuição dos resultados; iii) o feedback controlado; e iv) as respostas do grupo como um esforço consciente perante o consenso para a reavaliação de eventos futuros.

Na Figura 2, Skulmoski et al. (2007) apresentam, de maneira genérica, os passos esquematizados sobre como o método Delphi tem sido usado em projetos de pesquisa.

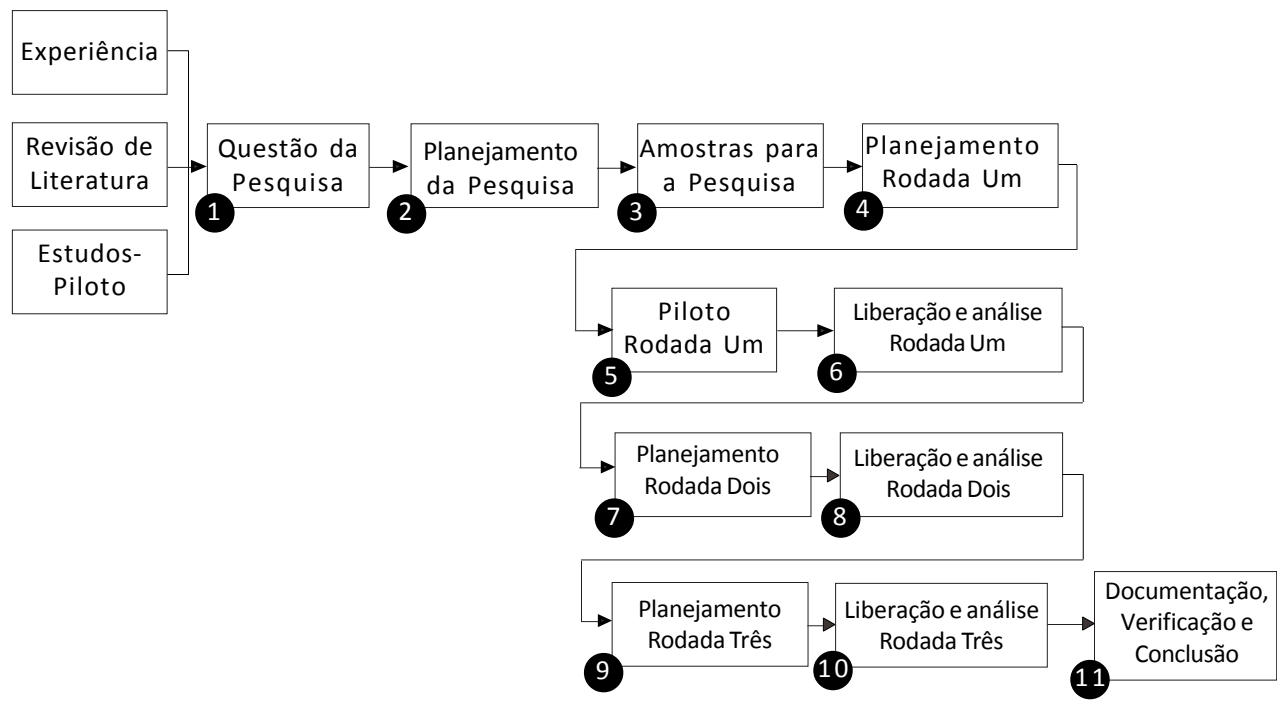

Fonte: Traduzido e adaptado de Skulmoski et al. (2007, p. 3).

Figura 2: Processo Delphi geral com três rodadas

\section{Aplicação do Método Delphi}

Esta pesquisa promoveu a ratificação, ou não, da lista inicial de FCS universais, trazendo-os para o contexto da APF brasileira.

Para tal, houve o auxílio de um grupo de especialistas em GTI na APF utilizando o método prospectivo Delphi. Submeteram-se os FCS universais iniciais à apreciação desses especialistas para que os mesmos analisassem, à luz de sua experiência pessoal/profissional e da realidade, características, contexto e cultura 
da APF brasileira, quais desses fatores realmente eram importantes, ou seja, eram críticos, vitais. Denominou-se esse processo de tropicalização ou "apfização" dos FCS universais.

Normalmente o método Delphi utiliza, em sua primeira rodada, um questionário aberto, com total liberdade para os participantes em suas respostas, cuja finalidade é ter um bom ponto de partida para as rodadas seguintes. Nesta pesquisa, optou-se por partir de uma lista reconhecida, colhida na literatura acadêmica especializada, a fim de ganhar tempo e focar a atenção dos especialistas naquilo que realmente é pertinente.

\section{Teste-piloto dos Questionários}

Testes de pré-aplicação foram realizados com os instrumentos de pesquisa propostos. No início da pesquisa de campo, o questionário da 1a rodada passou por um teste-piloto a fim de averiguar a clareza e compreensão do mesmo, bem como estimar o tempo necessário para o seu preenchimento. Participaram desse piloto cinco analistas, servidores públicos, com os seguintes perfis: dois doutores, dois mestres e um graduado nas áreas de Computação, Gestão Organizacional (Organização e Métodos - O\&M) e Matemática. Esses cinco testadores não foram convidados a responder à pesquisa como especialistas.

Após o teste-piloto algumas modificações foram promovidas no formulário com o propósito de torná-lo mais inteligível e ágil. Essas mudanças estruturais e semânticas fizeram com que o questionário da 1a rodada passasse de 35 para 40 fatores de sucesso submetidos. Entretanto, permitiram uma redução no tempo de resposta da ordem de $2 / 3$.

No que tange à 2a rodada, de posse do respectivo questionário, promoveu-se um teste simplificado do mesmo. Dessa vez os questionários foram testados, do ponto de vista da clareza e semântica, por três dos especialistas que responderam à 1a rodada, sem prejuízo. Afinal, essa rodada tratava-se de uma continuação da anterior. Nessa etapa da pesquisa, entende-se que os especialistas que responderam à 1 a rodada estavam mais contextualizados com a metodologia empregada do que os testadores que auxiliaram promovendo o teste-piloto. Com isso, ganhou-se tempo e sugestões de profissionais que já estavam integralmente comprometidos com o sucesso da pesquisa.

Outro importante fato a destacar relaciona-se aos instrumentos de feedback personalizados que foram encaminhados para os especialistas por ocasião do convite para a 2 a rodada. Esses também foram testados com esses três especialistas, de forma individualizada. 


\section{Primeira Rodada Delphi da Pesquisa}

Foram encaminhados, via e-mail, um total de 120 convites para profissionais de TI e GTI com experiência e militância em GTI na APF brasileira, convidando esses técnicos a participarem da pesquisa "Comitês de Governança de Tecnologia da Informação na Administração Pública Federal Brasileira: Fatores Críticos de Sucesso".

Os especialistas deveriam, portanto, opinar com base em um escala com itens do tipo Likert, sobre o grau de sua concordância com as afirmações apresentadas. Assim, as opiniões poderiam ser emitidas de acordo com um dos cinco pontos: discordo totalmente, discordo parcialmente, não concordo nem discordo, concordo parcialmente e concordo totalmente. Os especialistas também poderiam se abster de opinar.

O período de respostas da primeira rodada Delphi teve uma duração de 16 dias corridos com o formulário eletrônico on-line aberto para respostas, disponível no Google Docs. Uma versão “.doc" também estava disponível e foi encaminhada, a pedidos, para dois respondentes. Entretanto, todas as respostas recebidas foram processadas por meio da ferramenta de survey eletrônico do Google Docs.

Atenderam ao convite 78 profissionais de TI e GTI do serviço público, iniciativa privada e academia. Foi contabilizado, ao final do período, um total de 75 questionários recebidos, uma vez que 3 questionários não chegaram a ser transmitidos com êxito.

\section{Segunda Rodada Delphi da Pesquisa}

A segunda rodada apresentou aos especialistas um total de 20 fatores para avaliação. Oito deles eram oriundos da 1 ạ rodada, para reapreciação, já que não convergiram durante aquela rodada. Os 12 restantes eram oriundos dos 6 novos FCS (para cada nível de comitê) sugeridos pelos especialistas (e acatados) no decorrer da 1 a rodada para os dois níveis de comitê de GTI: estratégico e diretivo.

O questionário da 2a rodada foi encaminhado apenas para os 75 especialistas que responderam de forma válida à primeira rodada. Desses, 69 atenderam ao convite para a 2a rodada. O período de respostas da segunda rodada Delphi teve uma duração de 21 dias corridos com o formulário eletrônico on-line aberto para respostas, também disponível no Google Docs. Ao final da 2a rodada, alcançou-se a convergência de todos os fatores apresentados, exceto para um fator remanescente da $1^{\text {a }}$ rodada, que foi então declarado inconclusivo e descartado. 


\section{Análise e discussão de resultados}

Neste item são apresentados os principais resultados obtidos nesta pesquisa. Apresentam-se aqui os fatores referentes aos comitês estratégicos e diretivos de GTI na APF. Os quadros a seguir expõem para cada fator: o ordenamento, o número original, a afirmação, o status (no caso FCS ou FS), o CV (coeficiente de variação), que mede a homogeneidade dos dados em relação à média, o IIR (índice de importância relativa), que os classifica por importância relativa, e a rodada em que se obteve a convergência.

\section{Fatores Críticos de Sucesso para os Comitês Estratégicos de GTI na APF}

O Quadro 2 apresenta os 10 fatores reconhecidos, segundo a opinião dos especialistas, como fatores críticos de sucesso para os comitês estratégicos de GTI na APF. Nota-se que 7 deles advêm dos fatores universais extraídos da literatura e 3 advêm das sugestões dos especialistas durante as rodadas Delphi.

Decorre da lista que três temas se destacam: o alinhamento estratégico de negócio ( $\mathrm{TI})$, o comprometimento da alta administração e a colaboração por meio da organização (pan-organizacional). O primeiro com 3 fatores (01E, 02E e $27 \mathrm{E}$ ), o segundo com 2 fatores (41E e 36E) e o terceiro com 5 fatores (33E, 32E, $30 \mathrm{E}, 42 \mathrm{E}$ e $43 \mathrm{E}$ ). Em termos dos princípios da GTI, entende-se que esses fatores estão intrinsecamente relacionados ao alinhamento estratégico. Esse resultado é bastante expressivo, pois os especialistas confirmam indiretamente os problemas apontados pelo Levantamento de Governança de TI de 2012 realizado pelo TCU (BRASIL, 2012). A falta de comprometimento da alta administração com a GTI não endereça a integração colaborativa entre os setores de TI e negócio e impede um alinhamento estratégico mais adequado entre o negócio e a $\mathrm{TI}$.

\section{Fatores Críticos de Sucesso para os Comitês Diretivos de GTI na APF}

O Quadro 3 apresenta os 12 fatores reconhecidos, segundo a opinião dos especialistas, como fatores críticos de sucesso para os comitês diretivos de GTI na APF. Nota-se que 10 deles advêm dos fatores universais extraídos da literatura e 2 advêm das sugestões dos especialistas durante as rodadas Delphi.

Nesta lista de FCS, o princípio de alinhamento estratégico da GTI se mostra presente (41D, 02D, 30D, 01D e 15D) logo no início, como não poderia deixar de ser; mas também é possível perceber alguns outros fatores escolhidos que diferenciam o escopo de atuação desse nível de comitê. Segundo a opinião dos especialistas, percebe-se a preocupação com a apresentação de resultados. 0 princípio da GTI de gestão de riscos é endereçado por meio do fator 08D e o fator 
03D, de certa forma, busca trazer mais agilidade para a entrega de valor. Outra característica importante percebida está no estímulo à construção de relacionamentos, expressa pelo fator 15D. Dado o caráter mais tático/ operacional e menos estratégico, é possível perceber fatores mais estruturantes e que endereçam o modus operandi ideal para um colegiado como esse (21D, 03D, 05D e 44D).

Quadro 2: Relação de fatores críticos de sucesso para os comitês estratégicos de GTI na APF brasileira

\begin{tabular}{|c|c|c|c|c|c|c|c|}
\hline Ordem & $\#$ & Fator Crítico de Sucesso & Status & \%Pró & $\mathrm{CV}$ & IIR & Ronda \\
\hline 10 & $01 \mathrm{E}$ & $\begin{array}{l}\text { A manutenção de um enfoque } \\
\text { de negócio }\end{array}$ & FCS & 98.67 & 0.081 & 0.971 & $1 \underline{\underline{a}}$ \\
\hline 20 & 02E & $\begin{array}{l}\text { A busca de alinhamento estratégico } \\
\text { entre o negócio e a } \mathrm{TI}\end{array}$ & FCS & 96.00 & 0.105 & 0.971 & $1 \underline{\underline{a}}$ \\
\hline 3응 & $41 \mathrm{E}$ & $\begin{array}{l}\text { O reconhecimento, apoio e patrocínio } \\
\text { da alta administração }\end{array}$ & FCS & 95.59 & 0.129 & 0.965 & $2^{\mathrm{a}}$ \\
\hline 4음 & $36 \mathrm{E}$ & $\begin{array}{l}\text { A participação nesse colegiado de } \\
\text { membros da alta administração } \\
\text { (board) }\end{array}$ & FCS & 95.95 & 0.114 & 0.959 & $1 \underline{a}$ \\
\hline 50 & $33 \mathrm{E}$ & $\begin{array}{l}\text { A ampla representatividade dos } \\
\text { membros desse colegiado com } \\
\text { assentos para a alta administração, } \\
\text { negócio e TI }\end{array}$ & FCS & 97.30 & 0.111 & 0.957 & 1a \\
\hline 6o & $27 \mathrm{E}$ & $\begin{array}{l}\text { O alinhamento de seus membros com } \\
\text { os objetivos estratégicos do negócio }\end{array}$ & FCS & 93.24 & 0.146 & 0.946 & $1 \underline{\underline{a}}$ \\
\hline 70 & $32 \mathrm{E}$ & $\begin{array}{l}\text { A seleção e manutenção de membros } \\
\text { cooperativos, compromissados e } \\
\text { respeitados }\end{array}$ & FCS & 94.67 & 0.122 & 0.936 & $1 \underline{a}$ \\
\hline 80 & $30 \mathrm{E}$ & $\begin{array}{l}\text { O fomento entre os membros desse } \\
\text { colegiado de aprendizagem comparti- } \\
\text { lhada, respeito mútuo e confiança }\end{array}$ & FCS & 90.67 & 0.149 & 0.928 & $1 \underline{a}$ \\
\hline 9응 & $42 \mathrm{E}$ & $\begin{array}{l}\text { O reconhecimento e endereçamento } \\
\text { adequado das questões relacionadas } \\
\text { à cultura organizacional com enfoque } \\
\text { na promoção de mudanças organi- } \\
\text { zacionais }\end{array}$ & FCS & 95.59 & 0.135 & 0.924 & $2^{\mathrm{a}}$ \\
\hline 100 & $43 \mathrm{E}$ & $\begin{array}{l}\text { A capacitação de seus membros, bem } \\
\text { como da alta administração, em } \\
\text { governança corporativa de TI }\end{array}$ & FCS & 95.65 & 0.139 & 0.907 & $2^{\mathrm{a}}$ \\
\hline
\end{tabular}

Fonte: Elaboração própria. 
Quadro 3: Relação de fatores críticos de sucesso para os comitês estratégicos de GTI na APF brasileira

\begin{tabular}{|c|c|c|c|c|c|c|c|}
\hline Ordem & $\#$ & Fator Crítico de Sucesso & Status & \%Pró & $\mathrm{CV}$ & IIR & Ronda \\
\hline 10 & $41 \mathrm{D}$ & $\begin{array}{l}\text { O reconhecimento, apoio e patrocínio } \\
\text { da alta administração }\end{array}$ & FCS & 97.06 & 0.132 & 0.968 & $2^{\text {a }}$ \\
\hline 20 & 02D & $\begin{array}{l}\text { A busca de alinhamento estratégico } \\
\text { entre o negócio e a } \mathrm{TI}\end{array}$ & FCS & 98.55 & 0.104 & 0.942 & $1^{\underline{a}}$ \\
\hline 3은 & $32 D$ & $\begin{array}{l}\text { A seleção e manutenção de membros } \\
\text { cooperativos, compromissados e } \\
\text { respeitados }\end{array}$ & FCS & 95.71 & 0.118 & 0.937 & $1 \underline{a}$ \\
\hline 40 & 21D & $\begin{array}{l}\text { A frequência regular de encontros } \\
\text { desse colegiado }\end{array}$ & FCS & 94.29 & 0.123 & 0.937 & $1^{\text {a }}$ \\
\hline 5은 & 03D & $\begin{array}{l}\text { A busca, diante da constante e rápida } \\
\text { evolução/mudança tecnológica, } \\
\text { pela redução/eliminação de barreiras } \\
\text { burocráticas excessivas na organi- } \\
\text { zação com a finalidade de agilizar a } \\
\text { entrega de valor pela TI }\end{array}$ & FCS & 94.29 & 0.126 & 0.931 & $1 \underline{a}$ \\
\hline 6o & $30 \mathrm{D}$ & $\begin{array}{l}\text { O fomento entre os membros } \\
\text { desse colegiado de aprendizagem } \\
\text { compartilhada, respeito mútuo } \\
\text { e confiança }\end{array}$ & FCS & 92.86 & 0.141 & 0.931 & $1 \underline{a}$ \\
\hline 70은 & 01D & $\begin{array}{l}\text { A manutenção de um enfoque de } \\
\text { negócio }\end{array}$ & FCS & 97.10 & 0.116 & 0.930 & $1^{\underline{a}}$ \\
\hline 8ㅇ & 37D & $\begin{array}{l}\text { A participação nesse colegiado de } \\
\text { membros da gestão de TI }\end{array}$ & FCS & 95.65 & 0.143 & 0.928 & $1^{\text {a }}$ \\
\hline 9o & 15D & $\begin{array}{l}\text { O estímulo à construção de relacio- } \\
\text { namentos entre o negócio e a TI para } \\
\text { o alcance de pleno entendimento } \\
\text { mútuo e de senso de parceria }\end{array}$ & FCS & 94.03 & 0.131 & 0.922 & $1^{\underline{a}}$ \\
\hline 10 은 & 05D & $\begin{array}{l}\text { A manutenção de orientação no } \\
\text { sentido de uma atuação proativa }\end{array}$ & FCS & 92.86 & 0.146 & 0.917 & 1a \\
\hline 110 & 44D & $\begin{array}{l}\text { O estabelecimento de um "Regimento } \\
\text { Interno" que regule e oriente a } \\
\text { atuação desse colegiado }\end{array}$ & FCS & 95.59 & 0.127 & 0.915 & $2^{a}$ \\
\hline $12 \circ$ & 08D & $\begin{array}{l}\text { A promoção regular de rigorosa } \\
\text { vigilância, monitoração de deficiên- } \\
\text { cias e controle de riscos }\end{array}$ & FCS & 97.10 & 0.133 & 0.910 & 1a \\
\hline
\end{tabular}

Fonte: Elaboração própria. 


\section{Conclusões}

Este trabalho buscou identificar os fatores críticos de sucesso (FCS) para os comitês de governança de tecnologia da informação (CGTI) na administração pública federal (APF) brasileira. Partiu-se de um conjunto inicial composto de 40 fatores universais, colhidos na literatura acadêmica relacionada ao tema. Por meio do emprego do método Delphi, esse universo cresceu para 46 fatores e ao final de duas rodadas, com base nas percepções dos especialistas convidados para essa pesquisa, chegou-se aos seguintes resultados: i) para os comitês estratégicos de GTI na APF foram acolhidos como FCS um total de dez fatores; ii) para os comitês diretivos de GTI na APF foram acolhidos como FCS um total de doze fatores. Os demais fatores para ambos os níveis de comitês foram então considerados como fatores de sucesso (FS), excetuando-se um fator para o comitê estratégico, cujas opiniões dos especialistas não foram conclusivas.

Pode-se dizer que esses conjuntos de FCS obtidos (para os comitês estratégicos e diretivos), à luz das percepções dos especialistas participantes, são oficiosamente FCS organizacionais em suas respectivas organizações. No entanto, conforme pretendido, não se pode generalizar os resultados obtidos nesta pesquisa para toda a indústria APF brasileira.

A prática de GTI na APF brasileira é bastante recente e, como tal, ainda tem muito a aperfeiçoar e amadurecer. Novas pesquisas de maior amplitude podem ser conduzidas a fim de depurar e incrementar os resultados aqui alcançados. De qualquer forma, a lista de fatores críticos de sucesso apresentada é um valioso instrumento para aqueles profissionais responsáveis por planejar, implantar e/ ou sustentar programas de GTI em seus órgãos por meio do emprego das estruturas de comitês.

Duas importantes características dos FCS dizem respeito ao dinamismo e à temporalidade dos mesmos. Sabe-se que, com o decorrer do tempo, fatores de sucesso se tornam críticos, fatores críticos de sucesso deixam de ser críticos e surgem novos fatores. Isso principalmente em função do dinamismo sistêmico que circunda a vida das organizações e de seus gestores, imprimindo assim constantes e importantes mudanças em seus meio ambientes. Dessa forma, revisões periódicas devem ser realizadas nessas listas de FCS.

Vale ressaltar que foi realizado um teste de hipótese binomial para averiguar quais fatores manteriam a proporção superior a $90 \%$ de opiniões pró-FCS (concordo totalmente e concordo parcialmente), com o objetivo de inferir sobre o comportamento para a população real. Concluiu-se, com base nas percepções 
dos especialistas participantes, que a proporção real de especialistas que concordam total ou parcialmente que o "fator de sucesso é crítico" será superior a $90 \%(\mathrm{Ha})$, a $5 \%$ de significância, para os seguintes seis FCS:

- a manutenção de um enfoque de negócio é um FCS para os comitês estratégico e diretivo de GTI da APF;

- a busca de alinhamento estratégico entre o negócio e a TI é um FCS para o comitê diretivo de GTI da APF;

- a promoção regular de rigorosa vigilância, monitoração de deficiências e controle de riscos é um FCS para o comitê diretivo da APF;

- a ampla representatividade dos membros desse colegiado com assentos para a alta administração, negócio e TI é um FCS para o comitê estratégico de GTI da APF; e

- o reconhecimento, apoio e patrocínio da alta administração é um FCS para o comitê diretivo de GTI da APF.

Vislumbram-se alguns trabalhos futuros com temas correlatos aos da presente pesquisa:

i. realizar estudos de casos em órgãos da APF que tenham comitês de GTI implementados, no intuito de averiguar se os fatores identificados e avaliados nesta pesquisa são passíveis de aplicação em seus órgãos e se realmente se comportam como críticos, agregando algum diferencial para a governança de TI da organização;

ii. pesquisar o custo e o esforço de implementação associados a cada fator identificado nesta pesquisa, para a construção de um roadmap para implantação racional (custo/benefício) de fatores em órgãos da APF;

iii. confrontar os resultados dessa pesquisa com os de outras correlatas, verificando a pertinência de fatores, ordem de importância, aplicabilidade etc.; e

iv. realizar novo estudo com os membros de comitês dos órgãos do Sistema de Administração dos Recursos de Tecnologia da Informação (Sisp). Sugere-se, por exemplo, o emprego do método analítico hierárquico (AHP) e do método dos componentes principais para a identificação e o ordenamento dos fatores. 


\section{Referências bibliográficas}

All, S.; Green, P. Determinants of effective information technology governance: a study of IT intensity. In: Proceedings Of International It Governance Conference, 2005, Auckland, New Zealand. Anais... Auckland, New Zealand: 2005. Disponível em: < www.syaiful-ali.staff.ugm.ac.id/An_IT_Intensity_Study_2005.pdf >. Acesso em: 10 jan. 2013.

Bowen, P. L.; CheUnG, M. Y. D.; Rohde, F. H. Enhancing IT governance practices: a model and case study of an organization's efforts. International Journal of Accounting Information Systems, v. 8, n. 3, p. 191-221, 2007. Disponível em: < www.acc.ncku. edu.tw/chinese/faculty/shulc/courses/cas/articles/Bowen-enhancing-ITgoverance.pdf >. Acesso em: 10 jan. 2013.

BrasiL. Presidência da República. Decreto no 5.378/2005, 2005. Disponível em: <http:/ /www.planalto.gov.br/ccivil_03/_ato2004-2006/2005/Decreto/D5378.htm>. Acesso em: 16 jul. 2014.

Tribunal de Contas da União. Acórdão 1.603/2008 - TCU-Plenário, 2008a. Disponível em: <contas.tcu.gov.br/juris/Web/Juris/ConsultarTextual2/ Jurisprudencia.faces>. Acesso em: 10 jan. 2013.

Tribunal de Contas da União. Levantamento acerca da governança de tecnologia da informação na administração pública federal. Relator Ministro Guilherme Palmeira. Brasília: TCU (Sumários Executivos), Secretaria de Fiscalização de Tecnologia da Informação, 2008b. 48 p. Disponível em: < portal2.tcu.gov.br/ portal/pls/portal/docs/2056852.pdf >. Acesso em: 10 jan. 2013.

. Ministério do Planejamento, Orçamento e Gestão. Guia para criação e funcionamento do comitê de TI. Brasília: Ministério do Planejamento, Orçamento e Gestão (MPOG), Secretaria de Logística e Tecnologia da Informação (SLTI), 2011a. 73 p. Disponível em: < www.governoeletronico.gov.br/biblioteca/arquivos/guiapara-acriacao-e-funcionamento-do-comite-de-ti >. Acesso em: 10 jan. 2013.

Tribunal de Contas da União. Acórdão 2.585/2012 - TCU-Plenário, 2012. Disponível em: <contas.tcu.gov.br/juris/Web/Juris/ConsultarTextual2/ Jurisprudencia.faces>. Acesso em: 10 jan. 2013.

Bullen, C. V. Reexamining productivity csf's. Information Systems Management, v. 12, n. 3, p. 13-18, 1995. Disponível em: < dspace.mit.edu/bitstream/handle/1721.1/ 1988/SWP-1220-08368993-CISR-069.pdf?sequence=1 >. Acesso em: 10 jan. 2013.

Caporatello, L. IT governance: a framework proposal, and an empirical study. Rome, Italy. 2008. 137 p. Tese (Doutorado em Management Information Systems). LUISS University, Rome, Italy, 2008. Disponível em: < eprints.luiss.it/24/1/caporarello20080326.pdf >. Acesso em: 10 jan. 2013.

De HaEs, S.; VAn Grembergen, W. Moving from IT governance to enterprise governance of IT. Isaca Journal, v. 3, 2009. Disponível em: < www.isaca.org/Journal/Past-Issues/2009/ Volume-3/Documents/jpdf0903-moving-from-it-gov.pdf>. Acesso em: 10 jan. 2013. 
DoughtY, K. The myths and realities of IT steering committees. In: TINNIRELLO, P. C. (Org.). New directions in project management. Auerbach Publications, 2002. p. 235-243, cap. 21. Disponível em: <www.crcnetbase.com/doi/pdf/10.1201/ 9781420000160.ch21>. Acesso em: 10 jan. 2013.

DruRY, D. H. An evaluation of data processing steering committees. MIS Quarterly, v. 8, n. 4, p. 257-265, Dec. 1984. Disponível em: < www.jstor.org/stable/pdfplus/ 249095.pdf >. Acesso em: 10 jan. 2013.

Ferguson, C. R.; Dickinson, R. Critical success factors for directors in the eighties. Business Horizons May, june 1982. Disponível em: <pdn.sciencedirect.com/ science?_ob=MiamilmageURL\&_cid=272044\&_user $=1925346 \&$ \&ii $=$ 0007681382901239\&_check=y\&_origin=search\&_zone=rslt_list_item\&_coverDate= 1982-06-30\&wchp=dGLzVlt-zSkWA\&md5=f80a02d71f127d725e5c6ca227f1733c/1s2.0-0007681382901239-main.pdf >. Acesso em: 10 jan. 2013.

Gıovinazzo, R. A. Modelo de aplicação da metodologia Delphi pela internet: vantagens e ressalvas. Administração On Line Prática - Pesquisa - Ensino, FEA USP, v. 2, n. 2, abrmai-jun 2001. Disponível em: <www.fecap.br/adm_online/art22/renata.htm>. Acesso em: 10 jan. 2013.

GuLDENTOPS, E. Key success factors for implementing IT governance: let's not wait for regulators to tell us what to do. Information Systems Control Journal, v. 2, 2004. Disponível em: <www.isaca.org/Journal/Past-Issues/2004/Volume-2/ Documents/jpdf042-KeySuccessFactorsforlmp.pdf>. Acesso em: 10 jan. 2013.

GuPTA, Y. P.; RAghunAthan, T. S. Impact of information systems (IS) steering committees on IS planning. Decision Sciences, v. 20, i. 4, p. 777-793, fall 1989. Disponível em: <onlinelibrary.wiley.com/doi/10.1111/j.1540-5915.1989.tb01419.x/abstract>. Acesso em: 10 jan. 2013.

Huang, R.; Zmud, R. W.; Price, R. L. Influencing the effectiveness of IT governance practices through steering committees and communication policies. European Journal of Information Systems, n. 19, p. 288-302, june 2010. Disponível em: <www.palgrave-journals.com/ejis/journal/v19/n3/abs/ejis201016a.html>. Acesso em: 10 jan. 2013.

IT GovernanCE InSTITUTE - ITGI. IT governance global status report. 2004. 72p. Disponível em: < www.isaca.org/Knowledge-Center/Research/Documents/ITGI-GlobalStatus-Report-2004.pdf>. Acesso em: 10 jan. 2013.

JONKER, J. A. The strategic identification and integration of critical success factors to achieve international competitiveness for South Africa as a tourism destination. Pretoria, South Africa. 2004. 352 p. Tese (Doutorado em Commercii). University of Pretoria, Faculty of Economic and Management Sciences, Pretoria, South Africa, 2004. Disponível em: <upetd.up.ac.za/thesis/available/etd-07022004-130908/>. Acesso em: 10 jan. 2013.

Karimi, J.; BhattacherJee, A.; Gupta, Y.P.; Somers, T.M. The effects of MIS steering committees on information technology management sophistication. Journal of Management Information Systems, 17, 2, fall 2000. 
LuftMan, J. Competing in the information age: align in the sand. 2. ed. New York: Oxford University Press, 2003. 430 p.

Nfuka, E. N.; Rusu, L. Critical success factors for effective IT governance in the public sector organizations in a developing country: the case of Tanzania. In: 18th European Conference On Information Systems, 18., 2010. Anais... AIS Electronic Library (AISeL), 2010. Disponível em: <aisel.aisnet.org/ecis2010/128/>. Acesso em: 10 jan. 2013.

Nolan, R. L. Managing information systems by committee. Harvard Business Review, Boston, Massachusetts, v. 60, n. 4, p.72-79, 8p., jul-aug 1982.

Nolan, R.; Mcfarlan, F. W. Information Technology and the Board of Directors. Harvard Business Review, Boston, Massachusetts, v. 83, n. 10, p. 97-106, 10p., Oct 2005. Disponível em: <www3.fsa.br/LocalUser/gestaoti/ Ativ03\%20NOLAN\%202005\% 20\%20Information\%20Technology\%20and\%20the\% 20Board\%20of\%20Directors.. pdf>. Acesso em: 10 jan. 2013.

Prasad, A.; Heales, J.; Green, P. Towards a deeper understanding of information technology governance effectiveness : a capabilities-based approach. In: International Conference On Information Systems - Icis 2009, 2009. Anais... Disponível em: < accounting.uwaterloo.ca/uwcisa/symposiums/documents/ PrasadAcklesh.ppt >. Acesso em: 10 jan. 2013.

ReCK, R.; ReCK, V. P. Steering IS committees straight. Datamation, v. 35, n. 20, p. 8992, 4 p., 15 oct. 1989.

RockART, J. F. Chief executives define their own data needs. Harvard Business Review, Boston, Massachusetts, v. 57, n. 2, p. 81-92, 12p., Mar-Apr, 1979. Disponível em: $<$ hbr.org/product/chief-executives-define-their-own-data-needs/an/79209-PDFENG>. Acesso em: 10 jan. 2013.

Roldan, L. B.; Lenz, G. S.; Hansen, P. B. Fatores críticos de sucesso em redes interorganizacionais de cooperação: um ensaio teórico. In: Simpósıo De AdministraçÃo Da Produção, Logística E Operações Internacionals, 10, 2007, Rio de Janeiro. Anais... Rio de Janeiro: 2007. Disponível em: <www.raroefeito. com.br/ver/craweb/artigos/ fcs_em_redes_de_cooperacao.pdf >. Acesso em: 10 jan. 2013.

SKULMOSKI, G. J.; HARTMAN, F. T.; KRAHN, J. The Delphi method for graduate research. Journal of Information Technology Education, v. 6, p. 1-21, 2007. Disponível em: <jite.org/ documents/Vol6/JITEv6p001-021Skulmoski212.pdf>. Acesso em: 10 jan. 2013.

Van Grembergen, W.; De Haes, S. Enterprise governance of information technology: achieving strategic alignment and value. Springer Science, New York. Boston: Springer, 2009. $218 \mathrm{p}$.

Van Grembergen, W.; De Haes, S.; Guldentops, E. Structures, processes and relational mechanisms for IT governance. In: VAN GREMBERGEN, W. (Org.). Strategies for information technology governance. Antuérpia: Idea Group Publishing, 2004. p. 1-36.

Vezzoni, G. et al. Compreensão da relação entre fatores críticos de sucesso e o desempenho em projetos. In: Congresso Brasileiro de Gestão de Desenvolvimento de Produto, 8., 2011, Porto Alegre. Anais do 8o CBGDP. Porto Alegre: Fundação 
Empresa Escola de Engenharia UFRGS, v. 1, 2011. Disponível em: <www.ufrgs.br/ cbgdp2011/downloads/9024.pdf>. Acesso em: 10 jan. 2013.

VIEIRA, D. M. Governança de TI no setor público: caso DATAPREV. Niterói. 2005. 98 p. Dissertação (Mestrado em Sistemas de Gestão). Universidade Federal Fluminense, Niterói, 2005. Disponível em: <www.bdtd.ndc.uff.br/tde_arquivos/14/TDE-200610-03T100235Z-404/Publico/Dissertacao\%20DanieleVieira.pdf>. Acesso em: 10 jan. 2013.

WeILL, P.; Ross, J. W. IT governance on one page. CISR, Cambridge, v. 349, sloan wp n. 4516-04, 15 p., nov. 2004. Disponível em: <www.qavision.com/expertzone/ it_governance_in_a_page.pdf>. Acesso em: 10 jan. 2013.

Marcelo Silva Cunha

Mestre em Gestão do Conhecimento e da Tecnologia da Informação, pela Universidade Católica de Brasília (UCB). Contato: mscunha2000@gmail.com

João Souza Neto

Doutor em Engenharia Elétrica pela Universidade de Brasília (UnB), mestre em Engenharia Eletrônica pelo Philips International Institute da Holanda e professor do curso de Mestrado em Gestão do Conhecimento e da Tecnologia da Informação pela Universidade Católica de Brasília (UCB). Contato: joaon@ucb.br 